\title{
Analisis Posisi dan Upaya Peningkatan Indeks Daya Saing Daerah Pada Aspek Pilar Pendidikan Di Kabupaten Konawe Selatan
}

\author{
Ilyas \\ Universitas Halu Oleo, ilyasalimuddin@uho.ac.id
}

DOI

https://doi.org/10.26740/jupe.v10n1.p56$\underline{60}$

\author{
Article history \\ Received \\ 5 December 2021 \\ Revised \\ 10 December 2021 \\ Accepted \\ 12 December 2021
}

\section{How to cite}

Ilyas. (2022). Analisis Posisi dan Upaya Peningkatan Indeks Daya Saing Daerah Pada Aspek Pilar Pendidikan Di Kabupaten Konawe Selatan. Jurnal Pendidikan Ekonomi (JUPE), 10(1), 5660.

https://doi.org/10.26740/jupe.v10n1.p56$\underline{60}$

Kata Kunci: Daya Saing Daerah, Pilar Pendidikan, IPM.

Keywords: Regional Competitiveness, Education Pillar, HDI.

\section{Corresponding author}

Ilyas

ilyasalimuddin@uho.ac.id

\begin{abstract}
Abstrak
Penelitian ini bertujuan untuk mengetahui posisi dan upaya peningkatan Indeks Daya Saing Daerah pada pilar pendidikan di Kabupaten Konawe Selatan. Penelitian ini menggunakan pendekatan kuantitatif. Data yang digunakan adalah data primer dan data sekunder. Data primer diperoleh melalui kuesioner, sementara data sekunder berupa data IPM, tingkat pendidikan tenaga kerja diperoleh melalui studi dokumentasi/ publikasi dari Badan sat Statistik (BPS) dan Dinas Pendidikan Kabupaten Konawe Selatan. Teknik analisis data yang digunakan adalah analisis deskriptif. Hasil penelitian menunjukkan posisi Indeks Daya Saing Daerah Kabupaten Konawe Selatan berada pada posisi tinggi dengan nilai skoring 2,66. Upaya yang dilakukan untuk meningkatkan posisi daya saing daerah Kabupaten Konawe Selatan diantaranya peningkatan angka Rata-Rata Lama Sekolah; peran pemerintah daerah yang proaktif melakukan pendekatan persuasif kepada orang tua siswa; pemberian beasiswa bagi siswa kurang mampu; serta membuka akses yang lebih mudah kepada siswa untuk mendapatan layanan pendidikan.
\end{abstract}

\begin{abstract}
This study aims to determine the position and efforts to increase the Regional Competitiveness Index on the education pillar in Konawe Selatan Regency. This study uses a quantitative approach. The data used are primary data and secondary data. Primary data was obtained through a questionnaire, while secondary data in the form of HDI data, education level of the workforce was obtained through documentation/publication studies from the Statistics Agency (BPS) and the Education Office of South Konawe Regency. The data analysis technique used is descriptive analysis. The results showed that the Regional Competitiveness Index of South Konawe Regency was in a high position with a score of 2.66. Efforts made to improve the competitive position of the South Konawe Regency include increasing the average number of years of schooling; the role of local governments that are proactive in taking a persuasive approach to parents of students; providing scholarships for underprivileged students; as well as opening easier access for students to obtain educational services.
\end{abstract}




\section{PENDAHULUAN}

Pada tahun 2021, desentralisasi fiskal telah memasuki usia dua dekade. Beberapa capaian positif telah dicapai. Pada sisi ekonomi, desentralisasi fiskal telah memberikan peluang dan ruang bagi pemerintah daerah mengakselerasi pembangunan di daerah masing-masing. Adanya pelimpahan wewenang untuk mengatur dan mengurus daerah sendiri, sesuai dengan kebutuhan, potensi dan kearifan lokal daerah berhasil menjadi katalis pembangunan di daerah.

Konsep desentralisasi fiskal ini memberi kewenangan kepada pemerintah daerah untuk berinovasi, berkreasi menyusun strategi sendiri bagaimana membangun daerah masing-masing. Pemerintah daerah diberi kewenangan untuk mengelola keuangan, bagaimana mencari sendiri sumber pendapatan daerah,pun bagaimana membelanjakan uang mereka. Sesuai dengan kebutuhan di daerah masing-masing (Daris4e,2009). Dengan ini diharapkan akan mendorong penciptaan kesejahteraan di daerah.

Namun, di sisi yang lain, desentralisasi fiskal masih menyisakan beberapa ekses negatif yang bisa diidentifikasi dengan mudah seperti maraknya korupsi di daerah, ketergantungan fiskal daerah yang masih tinggi, termasuk juga persoalan masih banyaknya daerah yang memiliki daya saing yang rendah.

Seperti halnya daerah yang lain, Kabupaten Konawe Selatan tentu tidak lepas dari catatan-catatan kritis atas capaian-capaian pembangunan yang selama ini dilakukan. Salah satu catatan kritis yng dimaksud dalah pada aspek pendidikan. Sebagaimana publikasi BPS tahun 2021, Rata-rata lama sekolah di Kabupten Konawe Selatan masih tergolong rendah yakni 7,86 tahun pada tahun 2020 . Posisi ini hanya meningkat 0,12 poin dari tahun sebelumnya. Dengan kondisi rata-rata lama sekolah yang masih rendah ini, tentu akan berimplikasi pada kemampuan daya saing daerah.

Sebagaimana diketahui untuk meningkatkan kesejahteraan masyarakat mesti didukung oleh kemampuan daya saing masyarakat itu sendiri. Berbagai kajian empirik menunjukkan betapa daya saing berkontribusi sangat besat dalam peningkatan kesejahteraan masyarakat. Tingkat kesejahteraan yang tinggi di negara maju seperti di Amerika Serikat, Kanada, Jepang serta negara-negara Eropa Barat adalah justifikasi ilmiahnya.

Mengingat betapa pentingnya daya saing sebuah bangsa, maka daya saing tersebut menjadi tiga prioritas penting dari sembilan visi,misi dan program aksi Presiden Joko Widodo yang dikenal dengan sebutan Nawacita. Tiga prioritas yang terkait dengan daya saing adalah (1) meningkatkan kualitas hidup manusia,(2) meningkatkan produktivitas rakyat dan daya saing di pasar internasional dan (3) mewujudkan kemandirian ekonomi dengan menggerakan sektor-sektor strategis ekonomi domestik.

Untuk lebih memudahkan dan menjadi pedoman dalam upaya peningkatan daya saing tersebut maka Kemenristek/BRIN melalui Direktorat Sistem Inovasi, Deputi Penguatan Inovasi telah menginisiasi penyusunan model pengukuran Indeks Daya Saing Daerah (IDSD). Ini diharapkan dapat menggambarkan kondisi dan kemampuan suatu daerah dalam mengoptimalkan seluruh potensi yang dimilikinya melalui peningkatan produktivitas, nilai tambah dan persaingan baik domestik maupun internasional demi kesejahteraan yang tinggi dan berkelanjutan. IDSD juga dapat diartikan sebagai refleksi tingkat produktivitas, kemajuan, persaingan dan kemandirian suatu daerah. Pentingnya IDSD sebagai alat untuk menilai keberhasilan suatu daerah untuk dapat bersaing dengan daerah lain dan mendukung daya saing nasional (Kemenristek BRIN, 2020).

Indeks Daya Saing Daerah ini terdiri dari empat aspek, 12 pilar 23 dimensi dan 78 indikator. Salah satu pilar yang dimaksud adalah pilar pendidikan yang tercover dalam aspek kedua yakni aspek sumber daya manusia/ human capital.

Pilar pendidikan adalah pilar yang sangat penting dalam kehidupan negara.menjadi katalis yang paling rasional untuk mengakselerasi pembangunan ekonomi melalui peningkatan kualitas sumber daya manusia. Begitu pentingnya pendidikan ini, Dorris \& Naisbitt (2018) berani menyimpulkan bahwa untuk menguasai megatrends masa depan tak ada cara lain selain memberikan pendidikan terbaik kepada generasi muda.

Analisis dan pengukuran daya saing daerah saat ini menjadi salah satu dasar utama penyusunan dan penetapan kebijakan nasional maupun daerah yang akan mendorong pertumbuhan ekonomi dan kepemimpinan daerah yang inovatif.

Sebagai daerah otonom baru (dimekarkan sejak tahun 2003 dari kabupaten induknya yakni Kabupaten Konawe), sangat menarik untuk mengetahui capaian daya saing daerah Kabupaten Konawe Selatan. Khususnya pada aspek pilar pendidikan. Apalagi, Kabupaten Konawe Selatan memiliki potensi dan sumber daya yang besar sehingga sudah menjadi keharusan dalam merumuskan perencanaan pembangunan khususnya pada pilar pendidikan mesti mengawalinya dengan melakukan analisis posisi daya saing daerah. Kemudian merumuskan strategi peningkatan daya saing daerah pa aspek pilar pendidikan sehingga pencapaian visi-misi pemerintah daerah dapat tercapai dengan baik.

Berangkat dari paparan di atas, tulisan ini berusaha melihat posisi dan upaya peningkatan Indeks Daya Saing Daerah (IDSD) pada Pilar pendidikan di Kabupaten Konawe Selatan.

\section{METODE}

Penelitian ini menggunakan pendekatan kuantitatif. Populasi dalam penelitian ini adalah Kabupaten Konawe Selatan, Provinsi Sulawesi Tenggara. Karena penelitian ini fokus utuk mengukur Indeks Daya Saing Daerah pada pilar pendidikan maka yang djadikan sampel adalah Dinas Pendidikan Dan Kebudayaan Kabuapaten Konawe Selatan. Data yang digunakan adalah data primer dan data sekunder. Data primer diperoleh melalui kuesioner. Kuesioer yang digunakan diadopsi dari Kemenristek/BRIN (Deputi Penguatan Inovasi, 2020). Sementara itu data sekunder berupa data IPM, Harapan Lama Sekolah, Rata-Rata Lama Sekolah, serta tingkat pendidikan tenaga kerja diperoleh melalui studi dokumentasi/ publikasi dari BPS dan Dinas Pendidikan 
Kabupaten Konawe Selatan. Teknik analisis data yang digunakan adalah analisis deskriptif.

\section{HASIL DAN PEMBAHASAN}

\section{A. Posisi Indeks Daya Saing Kabupaten Konawe Selatan}

Dalam era otonomi daerah, dituntut peranan pemerintah daerah untuk memberikan kesejahteraan kepada masyarakat daerahnya dengan penyediaan public services yang sangat dibutuhkan (Simajuntak, 2015). Untuk meningkatkan kesejahteraan masyarakat maka menjadi penting untuk meningkatkan daya saing daerah. Daya saing daerah didefinisikan sebagai kemampuan perekonomian daerah dalam mencapai pertumbuhan tingkat kesejahteraan yang tinggi da berkelanjutan (Abdullah, 2002). Kementerian Riset dan Teknologi sendiri telah menyusun kategorisasi indeks daya saing daerah yang nilainya antara nol (0) sampai dengan lima. Semakin mendekati nol berarti Indeks Daya Saing Daerah (IDSD) semakin rendah, sebaliknya semakin mendekati 5 berarti IDSD sangat tinggi. Untuk lebih jelasnya dapat dilihat pada tabel di bawah ini:

Tabel 1. Klasifikasi Indeks Daya Saing Daerah

\begin{tabular}{ccc}
\hline No. & Kategori & Nilai IDSD \\
\hline 1. & Sangat Tinggi & $3,76-5,00$ \\
2. & Tinggi & $2,51-3,75$ \\
3. & Sedang & $1,26-2,50$ \\
4. & Rendah & $0-1,25$
\end{tabular}

Sumber: Kemenristek/BRIN, 2020

Klasifikasi IDSD terbagi atas 4 kategori yakni: Sangat Tinggi dengan rentang nilai antara 3,76- 5,00; Tinggi (2,51 - 3,75); Sedang (1,26 - 2,50); dan Rendah (0 $-1,25)$. Setiap daerah tentunya berharap memiliki IDSD yang terkategori Tinggi, atau setidaknya terkategori Tinggi, yang pasti tak ada daerah yang berharap berada pada kategori rendah. Semakin tinggi tingkat indeks daya saing daerah maka semakin tinggi pula tingkat kesejahteraan masyarakat (Syukri \& Wiwin, 2021).

Dengan adanya desentralisasi fiskal, dimana masing-masing daerah diberi kewenangan untuk mengatur dan menyusun sendiri sumber penerimaan serta pengeluraannya (APBD), maka diharapkan kewenangan tersebut bisa jadi tuas pengungkit mengkselerasi peningkatan Indeks Daya Saing Daerah. Konawe Selatan sebagai kabupaten yang baru terbentuk, yakni pada tahun 2003 tentu telah berupaya semaksimal mungkin meningkatkan IDSD, khususnya pilar pendidikan, agar bisa setara dengan daerah lainnya yang telah lebih maju. Untuk melihat IDSD pilar pendidikan di Kabupaten Konawe Selatan, dapat dilihat pada tabel 2 berikut ini:
Tabel 2. Skor Dimensi Daya Saing Daerah Pilar Pendidikan Kabupaten Konawe Selatan, 2021

\begin{tabular}{cccccc}
\hline No. & Dimensi & $\begin{array}{c}\text { Total } \\
\text { Skor }\end{array}$ & $\begin{array}{c}\text { Jumlah } \\
\text { Indikator }\end{array}$ & $\begin{array}{c}\text { Rerata } \\
\text { Skor }\end{array}$ & Kategori \\
\hline 1 & $\begin{array}{c}\text { Pendidikan } \\
\text { dan } \\
\text { Keterampilan }\end{array}$ & 18,64 & 7 & 2,66 & Tinggi \\
\hline
\end{tabular}

Sumber: Hasil olahan kuesioner

Berdasarkan tabel di atas menggambarkan dari 7 indikator pilar pendidikan, total skor yang diperoleh adalah 18,64 dengan rerata skor yakni 2,66. Dengan nilai, sebagaimana kategorisasi yang telah disusun oleh Kemenristek/BRIN maka dapat diketahui bahwa pilar pendidikan berada pada kategori "Tinggi". Ini adalah capaian yang sangat positif karena itu sepatutnya mesti diapresiasi. Mengingat sebagai Kabupaten yang baru dimekarkan, dengan usia saat ini 18 tahun (2003-2021) Kabupaten Konawe Selatan bisa mencatatkan IDSD Pilar Pendidikan berada pada kategori tinggi.

Capaian ini masih harus ditingkatkan. Menjadikan pilar pendidikan berada pada kategori "Sangat Tinggi”. Capaian positif pilar pendidikan, tak bisa dilepaskan dari kinerja indikator pendidikan positif pula. Misalnya dapat dilihat dari indikator Harapan Lama Sekolah dan Rata-Rata Lama Sekolah. Tabel berikutini menunjukkan Harapan Lama Sekolah dan Rata-Rata Lama Sekolah Kabupaten Konawe Selata tahun 2018-2020:

Tabel 3. Nilai Indikator IPM Dimensi Pendidikan Kabupaten Konawe Selatan Tahun 2018-2020

\begin{tabular}{|c|c|c|c|}
\hline $\begin{array}{ll}\text { Indikator } & \text { IPM } \\
\text { Dimensi } & \\
\text { Pendidikan } & \\
\end{array}$ & 2018 & 2019 & 2020 \\
\hline $\begin{array}{ll}\text { a. } & \text { Harapan } \\
\text { Lama } \\
\text { Sekolah } \\
\text { (Tahun) }\end{array}$ & 12,23 & 12,24 & 12,36 \\
\hline $\begin{array}{ll}\text { b. } & \text { Rata-Rata } \\
\text { Lama } \\
\text { Sekolah } \\
\text { (Tahun) }\end{array}$ & 7,73 & 7,74 & 7,86 \\
\hline
\end{tabular}

Sumber: BPS Kabupaten Konawe Selatan, 2021

Merujuk pada tabel 3. di atas, dapat diketahui bahwa dalam tiga tahun terakhir, Harapan Lama Sekolah dan Rata-Rata Lama Sekolah di Kabupaten Konawe Selatan terus mengalami peningkatan. Harapan lama Sekolah yang mencapai 12,36 tahun pada tahun 2020 mengandung arti bahwa anak-anak sekolah memiliki harapan lama sekolah selama 12,36 tahun atau setara dengan semester 1 di perguruan tinggi. Sementara RataRata Lama Sekolah di Kabupaten Konawe Selatan Setara dengan kelas VII pada Sekolah Menengah Pertama (SMP). Angka 7,86 tahun berarti sebelum menyelesaikan kelas VIII SMP, mereka berhenti sekolah.

Mesti diakui bahwa meskipun terus mengalami peningkatan, namun peningkatannya masih lambat. Bila ini mampu ditingkatkan dengan akselaratif misalnya Harapan Lama Sekolah menjadi 15 tahun dan Rata-Rata 
Lama Sekolah menjadi 9 tahun maka bisa dipastikan skoring IDSD pilar pendidikan akan meningkat pula. Selanjutnya untuk melihat bagaimana posisi pendidikan di daerah dapat dilihat dari capaian Indeks Pembangunan Manusianya (IPM), hal ini karena salah satu komposit pembentuk IPM adalah pendidikan. Tabel 4 di bawah ini menunukkan posisi IPM Kabupaten Konawe Selatan dan Provinsi Sulawesi Tenggara tahun 2016-2020:

Tabel 4. IPM Kabupaten Konawe Selatan tahun 20162020

\begin{tabular}{cccc}
\hline No. & Tahun & $\begin{array}{c}\text { IPM } \\
\text { Konawe } \\
\text { Selatan }\end{array}$ & $\begin{array}{c}\text { IPM Sulawesi } \\
\text { Tenggara }\end{array}$ \\
\hline 1. & 2016 & 66,97 & 69,31 \\
2. & 2017 & 67,23 & 69,86 \\
3. & 2018 & 67,51 & 70,61 \\
4. & 2019 & 67,88 & 71,20 \\
5. & 2020 & 68,20 & 71,45 \\
\hline
\end{tabular}

Sumber: BPS Kabupaten Konawe Selatan 2020.

Mencermati tabel di atas terlihat dengan jelas bahwa dalam lima tahun terakhir sejak tahun 2016 sampai tahun 2020, secara konsisten IPM Kabupaten Konawe Selatan mengalami peningkatan secara signifikan. Pada tahun 2016 IPM Konawe Selatan berada pada posisi 66,97 meningkat 1,23 poin menjadi 68,20 pada tahun 2020 . Capaian ini tentu perlu diapresiasi dan ditingkatkan. Mengingat jika dikomparasikan posisi IPM Kabupaten Konawe Selatan masih berada di bawah capaian IPM Provinsi Sulawesi Tenggara, yang pada tahun 2020 sudah berada di posisi 71,45 .

Apalagi di era Revolusi Industri 4.0 saat ini, utuk bisa sukses, setiap negara termasuk daerah dituntut untuk meningkatkan kualitas manusia, yang salah satu didukung oleh pendidikan yang berkualitas. Pilar pendidikan menjadi katalis paling rasional dan dominan dalam memacu pembangunan. Sangat banyak kajian yang membuktikan bahwa pendidikan adalah kunci sukses di masa depan (Dorris \& Naisbitt, 2018). Kemajuan negaranegara maju dominan didorong kemajuan pendidikan (Jhingan, 2008). Sebesar atau sebanyak apapun Sumber Daya Alam (SDA) yang dimiliki sebuah negara tanpa didukung oleh SDM maka tidak akan mampu untuk menjadikan kemakmuran sebuah negara (Amirudin, 2019).

\section{B. Upaya Meningkatkan Indeks Daya Saing Pilar Pendidikan Kabupaten Konawe Selatan}

Masalah ketenagakerjaan merupakan masalah penting dalam makro ekonomi, karena dari sisi penawaran (supply side) tenaga kerja merupakan salah satu faktor produksi selain modal, dan teknologi (Sasana, 2015). Salah satu faktor yang menentukan tingkat produktivitas tenaga kerja adalah pendidikan tenaga kerja itu sendiri.semakin tinggi tingkat pendidikan yag ditamatkan, maka terbuka peluang yang lebih besar untuk meningkatkan produktivitas, begitupun sebaliknya.

Pendidikan merupakan prasyarat kunci bagi pertumbuhan sektor-sektor pembangunan (Widiansyah,
207). Meningkatnya kualitas Sumber Daya Manusia (SDM) berjalan seiring dengan pertumbuhan ekonomi, hal ini dikarenakan SDM sebagai bagian dari faktor produksi yang merupakan aset paling berharga dalam aktivitas ekonomi sebuah wilayah (Raharti, dkk., 2020) Tabel berikut ini menunjukkan jumlah angkatan kerja menurut tingkat pendidikan di Kabupaten Konawe Selatan.

Tabel 5. Jumlah Angkatan Kerja Kabupaten Konawe Selatan Menurut Tingkat Pendidikan Tahun 2020.

\begin{tabular}{rcc}
\hline \multicolumn{1}{c}{ No. } & Tingkat Pendidikan & Jumlah \\
\hline 1. & $\leq$ Sekolah Dasar (SD) & 59.459 \\
\hline 2. & Sekolah Menengah Pertama & 34.788 \\
& (SMP) \\
\hline 3. & Sekolah Menengah Atas & 49.194 \\
& (SMA) \\
\hline Sumber: & BPS Kabupaten Konawe Selatan 2020
\end{tabular}

Tabel di atas menunjukkan bahwa tingkat pendidikan tenaga kerjadi Kabupaten Konawe Selatan didominasi oleh tamatan SMA ke bawah. Persentasenya sebanyak persen. Bahkan yang paling banyak adalah tenaga kerja dengan pendidikan $\leq$ Sekolah Dasar $(\mathrm{SD})$ sebanyak 59.459 jiwa $(36,75$ pesen). Sementara tenagakerja yang berpendidikan tamatan perguruan tinggi hanya sebanyak 18.361 jiwa (11,35 persen).

Komposisi tenaga kerja yang masih didominasi oleh tenaga kerja berpendidikan SMA ke bawah merupakan tantangan yang mesti diselesaikan oleh Pemerintah Daerah Kabupaten Konawe Selatan. Hal ini karena tingkat pendidikan memiliki linearitas dengan produktivitas tenaga kerja, yang muaranya adalah pertumbuhan dan pembangunan ekonomi serta kesejahteraan masyarakat. Sementara itu dari penelitian (Rizal, 2015) menemukan bahwa tenaga kerja dengan jenjang pendidikan lebih tinggi signifikan mengurangi kemiskinan di Indonesia. Pada umumnya seseorang yang memiliki tingkat pendidikan yang lebih tinggi akan mempunyai wawasan yang lebih luas untuk meningkatkan kinerjanya (Putri \& Sri, 2017)

Ada beberapa upaya yang bisa dilakukan untuk meningkatkan daya saing pilar pendidikan di Kabupaten Konawe Selatan diantaranya: Pertama, dengan merujuk pada data peningkatan Rata-Rata Lama Sekolah yang tergolong lambat, maka perlu adaya effort yang kuat dari pemerintah daerah agar perkembangannya akseleratif. Apalagi saat ini pemerintah pusat telah mencanangkan program wajib belajar 12 tahun. Sehingga dengan pencapaian Rata-Rata Lama Sekolah saat ini yang berada pada angka 7,86 tahun, mengharuskan adanya terobosanterobosan dari Pemerintah Daerah agar Rata-Rata Lama bisa meningkat, minimal sesuai dengan program wajib belajar 12 tahun tersebut.

Kedua, Pemerintah Daerah Konawe Selatan melalui dinas terkait, khususnya Dinas Pendidikan perlu 
pro aktif dan melakukan pendekatan persuasif terhadap orang tua siswa. Fakta menunjukkan bahwa tak jarang anak menjadi putus sekolah karena perintah dari orang tua mereka sendiri. Bagi sebagian orang tua menyekolahkan anak tak lebih dari menambah beban keluarga. Lebiha baik mereka berhenti sekolah kemudian membantu pekerjaan orang tua. Dengan ini anak tersebut bisa meringankan beban orang tua, dan tentu saja menambah penghasilan keluarga. Pemerintah Daerah Konawe Selatan harus memberi penyadaran dan meyakinkan para orang tua, betapa pentingnya pendidikan untuk masa depan mereka. Pendidikan bukanlah beban, tetapi investasi yang akan dinikmati hasilnya di kemdian hari. Para orang tua harus diberi pemahaman bahwa pendidikan adalah katalis paling rasional untuk mengangkat status sosial dan status ekonomi mereka.

Ketiga memberikan beasiswa pendidikan bagi siswa yang kurang mampu secara ekonomi. Salah satu faktor yang membatasi akses masyarakat terhadap pendidikan adalah faktor biaya (Mahendra, dkk., 2016). Pemberian beasiswa oleh pemerintah daerah kepada siswa dari keluarga kurang mampu adalah salah satu konkret mengatasi problem biaya yang dihadapi oleh keluarga kurang mampu tersebut. Ini merupakan salah satu solusi Hal ini memungkinkan karena sebagaimana diketahui bahwa sesuai Undang-Undang Nomor 20 tahun 2003 tentang Sistem Pendidikan nasional mengamnatkan alokasi anggaran untuk pendidikan sebesar 20 persen dari APBD. Angka 20 persen ini sangatlah besar, sehingga memberi ruang dan peluang bagi Pemerintah Daerah Konawe Selatan untuk menyusun program yang bisa secara langsung berpengaruh terhadap peningkatan RataRata Lama Sekolah. Seperti pemberian beasiswa bagi siswa yang kurang mampu.

Keempat, mempermudah akses terhadap layanan pendidikan. Tak bisa dipungkiri bahwa banyak siswa yang putus sekolah karena ketidakmampuan mereka mengakses layanan pendidikan tersebut. Misalnya saja jarak antara sekolah dan rumah yang jauh; infrastruktur yang tidak mendukung seperti jalan rusak dan ketiadaan kendaraan umum. Problem semacam ini bisa diatasi dengan membangun gedung sekolah yang dekat pemukiman, memperbaiki jalan dan infrastruktur lainnya. Termasuk pula pengadaan bus sekolah gratis. Program semacam ini tentu membuka akses yang lebih luas bagi siswa untuk mendapatkan layanan pendidikan, sehingga akan menekan angka putus sekolah.

Program-program ini bila dilaksanakan dengan baik maka bermuara pada peningkatan rata-rata lama sekolah. Pastinya akan meningkatkan pilar pendidikan. Selanjutnya bila pendidikan masyarakat mengalami peningkatan akan berkorelasi postif terhadap peningkatan Indeks Daya Saing Daerah Kabupaten Konawe Selatan.

\section{SIMPULAN}

Ada beberapa hal yang daapat disimpulkan dalam penelitian ini yakni: posisi Indeks Daya Saing Daerah Kabupaten Konawe Selatan berada pada posisi tinggi dengan nilai skoring 2,66. Upaya yang dilakukan untuk meningkatkan posisi daya saing daerah Kabupaten Konawe Selatan diantaranya peningkatan angka Rata-Rata
Lama Sekolah; peran pemerintah daerah yang proaktif melakukan pendekatan persuasif kepada orang tua siswa; pemberian beasiswa bagi siswa kurang mampu; serta membuka akses yang lebih mudah kepada siswa untuk mendapatan layanan pendidikan.

\section{DAFTAR PUSTAKA}

Abdullah, Petter. (2002). Daya Saing Daerah Konsep dan Pengukurannya Di Indonesia. Yogyakarta: BPFE.

Amirudin, M.F. (2019). Hubungan Pendidikan dan Daya Saing Bangsa. Belajea : Jurnal Pendidikan Islam, 4(1), pp. 35-48. doi: 10.29240/belajea.v4i1.723

Bank Dunia. (2000). Kualitas Pertumbuhan. Jakarta: PT. Gramedia Pustaka Utama

BPS. (2021). Indeks Pembangunan Manusia Kabupaten Konawe Selatan. BPS Konawe Selatan.

Darise, Nurlan. (2009). Pengelolaan Keuangan Daerah. Jakarta: PT Indeks.

Dorris \& John Naisbitt. (2018). Mastering Megatrends. Jakarta: Bhuana Ilmu Populer.

Jhingan, M.L. (2008). Ekonomi Pembangunan dan Perencanaan. Jakarta: PT. RajaGrafindo Persada.

Mahendra, Roy., dkk. (2016). Strategi Peningkatan Indeks Pendidikan Melalui Alokasi Belanja Pemerintah Daerah Bidang Pendidikan Di Provinsi Jawa Timur. Jurnal Manajemen Pembangunan Daerah, 8 (2), pp. 1-19.

Marsuki. (2005). Analisis Perekonomian Sulawesi Selatan dan Kawasan Timur Indonesia. Jakarta: Penerbit Mitra Wacana Media.

Putri, Y.A.K.D, \& Sri Kusreni. (2017). Analisis Pengaruh Tingkat Kesehatan, Tingkat Pendidikan, Dan Upah Terhadap Produktivitas Tenaga Kerja Di Indonesia. JIEP, 17(2), pp. 67-77.

Raharti, Rini, dkk. (2020). Analisis Pertumbuhan Ekonomi Dan Indeks Pembangunan Manusia Di Daerah Istimewa Yogyakarta. Jurnal Perspektif Ekonomi Darussalam, 6 (1), pp. 36-53.

Ristek BRIN. (2020). Panduan Indeks Daya Saing Daerah 2020. Jakarta.

Rizal, R.N. (2015). Apakah Jenjang Pendidikan Dasar Tenaga Kerja Berperan dalam Mengurangi Kemiskinan di Indonesia? Jurnal Ekonomi dan Pembangunan Indonesia, 16 (1), pp. 15-30. doi: http://dx.doi.org/10.21002/jepi.v16i1.596

Sasana, Hadi (2015). Dampak Implementasi Desentralisasi Fiskal Terhadap Pertumbuhan Ekonomi Dan Stabilitas Harga Di Provinsi Di Indonesia. Jurnal Media Ekonomi dan Manajemen, 30 (1), pp. 1-14.

Simajuntak, K.M. (2015). Implementasi Kebijakan Desentralisasi Pemerintahan Di Indonesia. Jurnal Bina Praja, 7 (2), pp. 111-130

Syukri, A.F., \& Wiwin Widiastuti. (2021). Evaluasi Kebijakan Pembangunan Daerah Di Provinsi Jawa Tengah 2019. Jurnal Ilmu Administrasi Publik, 6 (1), pp. 42-52. doi: Prefix 10.26905.

Widiansyah, Apriyanti. (2017). Peran Ekonomi dalam Pendidikan dan Pendidikan dalam Pembangunan Ekonomi. Cakrawala, 12 (2), pp. 207-215. 